\title{
Robotic adrenalectomy: when and how?
}

\author{
Claire Nomine-Criqui ${ }^{1}$, Lea Demarquet ${ }^{2}$, Marie Laure Schweitzer $^{2}$, Marc Klein ${ }^{2}$, Laurent Brunaud ${ }^{1,3}$, \\ Florence Bihain ${ }^{1}$
}

${ }^{1}$ Unit of Metabolic, Endocrine, and Thyroid Surgery (UMET), Department of Visceral and Metabolic Surgery, Hospital Brabois Adultes, CHRU Nancy, ${ }^{2}$ Department of Endocrinology, Diabetology and Nutrition, CHU Nancy, ${ }^{3}$ INSERM U1256, Nutrition, Genetics, Environmental Risks, Faculty of Medicine, University of Lorraine, Nancy, France

Contributions: (I) Conception and design: L Brunaud; (II) Administrative support: None; (III) Provision of study materials or patients: None; (IV) Collection and assembly of data: None; (V) Data analysis and interpretation: L Brunaud; (VI) Manuscript writing: All authors; (VII) Final approval of manuscript: All authors.

Correspondence to: Claire Nomine-Criqui, MD. Unit of Metabolic, Endocrine, and Thyroid Surgery (UMET), Department of Visceral and Metabolic Surgery, Hospital Brabois Adultes, CHRU Nancy, University of Lorraine, Nancy, France. Email: claire.nomine@gmail.com;

c.nomine-criqui@chru-nancy.fr.

\begin{abstract}
Currently, laparoscopic adrenalectomy is considered as the preferred technique to manage adrenal tumors. However, there are no prospective randomized studies evaluating this strategy. With the recent advances in surgical equipment and the widespread of robotic technology, a robotic approach is considered as an interesting option in some medical centers. This approach seems to be feasible and safe but high-level evidence of its benefits is still lacking. This review summarizes indications, advantages and drawbacks of robotic adrenalectomy and describes its surgical technique.
\end{abstract}

Keywords: Adrenal; robotic; adrenalectomy; pheochromocytoma

Submitted Nov 04, 2019. Accepted for publication Dec 06, 2019.

doi: 10.21037 /gs.2019.12.11

View this article at: http://dx.doi.org/10.21037/gs.2019.12.11

\section{Introduction}

Mini invasive adrenalectomy (laparoscopic and robotic) has been widely adopted for over more than 10 years because it improves peri-operative results and decreases hospitalization stay compared to open adrenalectomy $(1,2)$. Robotic adrenalectomy (RA) seems to be as safe and feasible than laparoscopic adrenalectomy (LA) yet large, randomized, and prospective studies are still lacking. Ultimately, in which situations RA can be performed with relevance? In our experience, all adrenalectomies are routinely performed with a robotic approach apart from very large adrenocortical tumors with adjacent organ extension. Nonetheless, we are convinced that the robotic tool can be particularly useful when concerning obese patients [body mass index (BMI) $\left.>30 \mathrm{~kg} / \mathrm{m}^{2}\right]$, large tumors $(>6 \mathrm{~cm})$ and patients who previously had abdominal surgery.

\section{Methods}

A systematic search was performed using the database PubMed. We screened eligible studies by using several keywords such as: "robotics", "laparoscopy" and "adrenalectomy". We restricted the suitable studies to human subjects and publications in English. A total of 234 studies were identified, reporting the technique and perioperative outcomes of robot assisted adrenalectomy. The principles of Helsinki declaration were followed in this review.

\section{Robotic compared to laparoscopic approach- feasibility and safety}

Screening of literature clearly shows that RA is as feasible and as safe as LA. Unfortunately, large prospective 
Table 1 Perioperative outcomes after robotic transabdominal adrenalectomy

\begin{tabular}{|c|c|c|c|c|c|c|c|c|}
\hline Year & Author & Patients (n) & $\begin{array}{l}\text { Operative } \\
\text { time (min) }\end{array}$ & Tumor size $(\mathrm{cm})$ & Conversion (n) & Morbidity (\%) & Mortality (\%) & $\begin{array}{c}\text { Hospital stay } \\
\text { (days) }\end{array}$ \\
\hline 2006 & Winter (12) & 30 & 185 & 2.4 & 0 & 7 & 0 & 2 \\
\hline 2011 & Giulianotti (4) & 42 & $118 \pm 46$ & 5.5 & 0 & 2.4 & 2.38 & 1 \\
\hline 2013 & Aksoy (15) & 42 & 186 & 4 & 0 & 4.7 & 0 & 1.3 \\
\hline 2012 & D'Annibale (6) & 30 & $231 \pm 46$ & 5.1 & 1 & 10 & 0 & 5.2 \\
\hline 2013 & Aliyev (16) & 26 & 149 & - & 1 & 0 & 0 & 1.2 \\
\hline
\end{tabular}

randomized studies are lacking and there is currently no proven advantage of the use of robotic. With a robotic approach, it has been shown that a learning curve of 20 cases is required. This corresponds to the number of patients necessary to obtain a similar outcome than when performing LA $(3,4)$. This means that a surgeon needs to perform 20 robotic adrenalectomies to obtain a similar outcome than when performing LA $(3,4)$. We have experienced in our center that operative time decreases significantly between the first 50 surgeries and the last 45 . This difference was particularly striking when concerning junior surgeons: from 123 to $97 \mathrm{~min}$ for junior surgeons and from 90 to $81 \mathrm{~min}$ for senior surgeons (5). D'annibale et al. showed similar results with a significant decrease between the first five cases and the last five cases (30 adrenalectomies-296 versus $168 \mathrm{~min}, \mathrm{P}=0.013$ ) (6).

However, these results were not found in all studies. Indeed, several studies comparing the laparoscopic approach to the robotic approach had divergent results as regards to the operative time. Indeed, for Pineda-Solís et al. and You et al., the mean operative time was longer in the robotic group patients and this difference was attributed to docking time $(7,8)$. Docking time should be taken into account when comparing RA and LA because it can increase mean operative time by 15 to $40 \mathrm{~min}$ and can go up to $1 \mathrm{~h}$ during the first cases. We observed that surgeon experience, first assistant training level and tumor size remained independent factors associated with mean operative time $(5,9)$. Makay et al. observed in a recent review that at the onset of surgical experience there was a longer operative duration when concerning the robotic approach (10). In another meta-analysis, Heger et al. showed no differences in terms of operative time between laparoscopic and robotic approach (11).

To this day, based on available data we can affirm that there is no difference between the robotic approach and the laparoscopic approach as regards to mortality and morbidity (Table 1). In a large meta-analysis that included 1,162 cases, Economopoulos et al. (747 robotic and 415 laparoscopic adrenalectomies from 27 studies) revealed that there was no significant difference between the two approaches in terms of intra operative complications [odds ratio (OR): 1.2; $95 \%$ confidence interval (CI), 0.33-4.38], post-operative complications (OR: $0.69 ; 95 \%$ CI, $0.36-1.31$ ), and mortality (OR: 0.42; 95\% CI, 0.07-2.72) (20).

Overall, we can attest that the robotic approach is feasible and safe. Indeed, there are more than 200 studies dealing with the subject and in each of them there is no difference in terms of morbidity and mortality. In our opinion, we think that the use of the robot is an indisputable asset for a junior surgeon. For instance, a non-experienced surgeon can learn the different techniques side by side with a senior surgeon with the use of the second console. And when comes the time of the first adrenalectomy for a young surgeon, he/she is more prepared and so, there may be less morbidity and a quicker operative time. However, this is only an opinion based on our clinical experience, and there is a need for prospective comparative studies to validate this hypothesis. 


\section{Transperitoneal or retroperitoneal adrenalectomy?}

Two techniques are currently described for adrenalectomy: transperitoneal adrenalectomy and retroperitoneal adrenalectomy. Kahramangil et al. showed in a study based on 200 adrenalectomies that the two approaches seemed to be equally safe (21). The American Society for Gastrointestinal and Endoscopic Surgery (SAGES) has provided recommendations supposed to guide surgeons between the two approaches (22). This society recommends retroperitoneal approach for bilateral adrenalectomy and for patients with previous abdominal surgery. To them transperitoneal approach seems to be particularly interesting in obese patients and for large tumors $(>6 \mathrm{~cm})$.

\section{RA for adrenocortical tumors}

Adrenocortical cancer is rare but aggressive. Local and distant recurrences are reported in $85 \%$ of patients at 5 years after resection. Complete resection with negative margins and no capsular effraction are the most important conditions to offer a chance of cure. In a recent comparative retrospective study, 238 laparoscopic adrenalectomies for non-metastatic primary malignancy were compared to 51 robotic adrenalectomies for the same pathology (23). The rate of open conversion was lower in the robotic group (5.9\% vs. $17.2 \% ; \mathrm{P}=0.04)$. No difference was found in regards of positive margin, lymphadenectomy, hospital stay, readmission and mortality.

In this study of Mishra et al., robotic approach seems to decrease conversion rate and perhaps may improve feasibility of surgery (23).

\section{Adrenalectomy in patients with large tumors}

Large tumors resection (mainly pheochromocytoma and adrenocortical carcinoma) are associated with the risk of intraoperative capsular effraction and the risk of local recurrence $(24,25)$. At first, it was considered to be very difficult to pursue laparoscopic resection in those cases. But over time, specialized teams have gained experience and skills. The threshold of what is considered to be large is from $6 \mathrm{~cm}(26,27)$. Some authors showed that surgery of large adrenal tumors is feasible by laparoscopic or robotic approach (9), and some data emphasized that robotic approach is particularly interesting in these cases because it decreases operative time in this subgroup of patients. Morelli et al. seem to confirm these results with a shorter operative time in robotic group patients with large tumors ( $>6 \mathrm{~cm}$ ) (28). Resection of large adrenal tumors can be challenging in restricted retroperitoneal space; they recommend avoiding robotic retroperitoneal approach in patients with larger tumors and to prefer the use of a transperitoneal approach in those patients.

Thompson et al. used the Swedish database including 659 adrenalectomies (37.9\% were robotically assisted) to evaluate the role of a robotic approach in patients with large tumors (29). In this nationwide database, a robotic approach was used preferentially in larger tumors. Their data suggests that there may be some benefits to the use of the robotic system in those patients and that it could avoid conversion to laparotomy and so decrease postoperative morbidity. However, these conclusions need to be put in perspective; many other authors have different findings. In a recent literature review, Ball et al. reported that no prospective studies have been published on the robotic approach in patients with large tumor including adrenocortical carcinoma (30). Furthermore, results of retrospective studies comparing laparoscopic versus open approach for adrenocortical carcinoma were still controversial. Consequently, it was concluded that while laparoscopic approach seemed to be feasible in selected cases without any adjacent organs involvement, open approach should still be preferred to laparoscopic or robotic approach for adrenocortical carcinoma.

\section{RA in obese patients}

Perioperative outcomes in obese patients are controversial but, some data suggest that the robotic approach is safe without any increase of morbidity. In our center, we showed that BMI had no incidence on operative time (5) and that the robotic system could offer some advantages in obese patients. In a study that included 99 obese patients (BMI $>30 \mathrm{~kg} / \mathrm{m}^{2}$ ), Aksoy et al. showed that the conversion rate was higher in the laparoscopic group (5.2\% vs. $0 \%)$ than in the robotic group $(\mathrm{P}=0.006)(15)$. In this study, perioperative outcomes were the same in the two groups. In 2016, Morelli et al. showed in a comparative study that robotic approach decreased operative time in obese patients (28). These data diverge from the recent results of Agcaoglu et al. (14). In this retrospective study, 26 obese patients were compared to 40 non-obese patients. No difference was found in terms of operative time, blood loss, conversion rate and length of stay. 


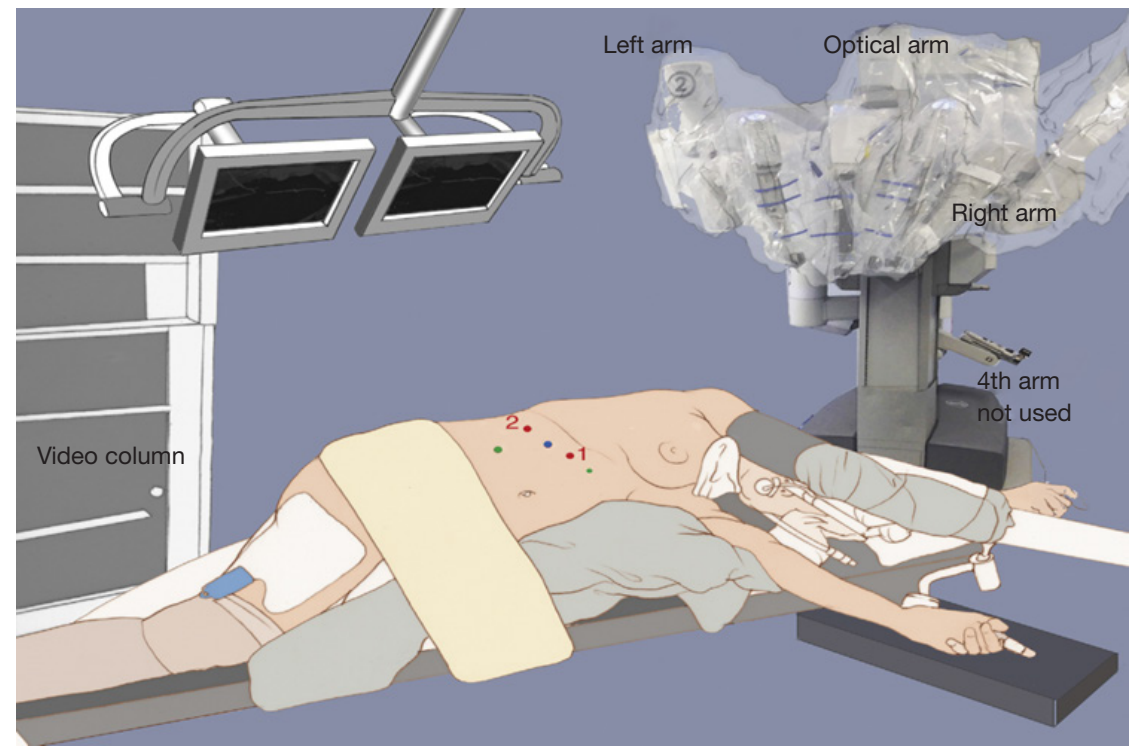

Figure 1 Patient positioning for a right adrenalectomy.

In the study of Greilsamer et al. (19) that included 303 unilateral robotic transabdominal adrenalectomies, $30 \%$ of patients had a BMI $>30 \mathrm{~kg} / \mathrm{m}^{2}$ and no difference were found in terms of operative time and perioperative complications. The same results were found by Coste et al. for laparoscopic adrenalectomies (31). Data are lacking to emphasize interest of the robotic approach in obese patient, some results suggesting a superiority of the robotic approach and some others showing that the difficulty to maintain exposure in obese patient could nullify the interest of robotic instruments. But with the demographic changes that are upon the American and European patients, there is a need to consider the problems that surgeons are faced with when operating on obese patients.

\section{Costs}

A major drawback of the robotic approach is its cost. Overcost is variable between studies but constant and consequent. In a retrospective comparative study between laparoscopy and robotic, Samreen et al. showed that total charges of RA was about 42,659 dollars whereas laparoscopic approach was around 33,748 dollars (32). Bodner et al. showed that RA was 1.5 more expensive than conventional minimally invasive surgery (33). Feng et al. (34) compared the two approaches and calculated a relative cost of 3,527 dollars for robotic procedure and of 3,430 dollars for LA and without any difference in regards of operative and anesthesia times. In this study, the authors supposed that the cost of robotic surgery can be compared to laparoscopic surgery by limiting the number of robotic instruments and energy devices by an experienced surgical team.

In that regard, is there any advantages of robotic surgery that can offset its overcost? From the patient view, differences between the two approaches may be tenuous. However, for surgeons, robotic surgery is much more comfortable than laparoscopic surgery. Indeed, in a survey from Stanford University, $55.4 \%$ of 1,215 surgeons attributed their symptoms to laparoscopic surgery, $36.3 \%$ to open surgery, and only $8.3 \%$ to robotic surgery (35). And in another study, surgeons practicing laparoscopy had a 2-3 times higher risk of becoming unfit for work overtime (36). Overall, this data needs to be studied more precisely and may be an argument in favor of a robotic approach on a regular basis.

\section{How? —surgical technique (37)}

Surgery is performed under general anesthesia. No antibiotic is needed during adrenalectomy.

\section{Patient positioning}

Patient is positioned (Figure 1) in strict lateral decubitus. A bolter pillow is inserted underneath the patient just below the costo-diaphragmatic angle to open the surgical area. 
Flexion is given to the operating table and legs are lowered. The homolateral arm has to be specially taken care of because of the risk of plexus brachial injury.

\section{Trocar arrangement}

It is the most important step of the procedure. Trocars have to be well positioned to avoid contact pressure points and conflicts between the robotic arms. The first inserted trocar is the optical trocar (blue on the figure), which is placed two finger's breadth beneath the costal margin by open laparoscopic technique, the peritoneal cavity is then insufflated. The two robotic trocars $(8 \mathrm{~mm}-1$ and 2 red on the figure) are inserted and placed under camera control.

For a right adrenalectomy, a $10-\mathrm{mm}$ trocar for a fan liver retractor and a $5-\mathrm{mm}$ trocar for the assistant's left hand are added (in green on the figure). For a left adrenalectomy, only one $5-\mathrm{mm}$ trocar for the assistant is added.

After this step, the circulating nurse places the robotic cart at 11 o'clock from the patient head for a right adrenalectomy and at 1 o'clock for a left adrenalectomy. The robotic instruments are attached to the three arms of the robotic patient trolley (telescope and both robotic arms).

\section{Console time}

Whatever the side of the pathologic gland there are five steps for adrenalectomy: exposure of the right/left side, control of the main adrenal vein, glandular dissection, end of dissection, end of the operation.

There are anatomical specificities for each side.

On the right side, the adrenal gland is easily visualized, behind the right lobe of the liver and lateral to the retrohepatic vena cava. The liver retractor mobilizes the right hepatic lobe in order to expose the right adrenal gland and then the main adrenal vein. The peritoneum is incised in front of the adrenal gland until the right edge of the inferior vena cava is exposed above the take off of the right renal vein. The right adrenal vein is sectioned after a clip has been applied by the surgeon.

On the left side, the gland is more difficult to visualize. The first step is to mobilize the spleen upward to visualize the stomach and to also mobilize the pancreas' tail to expose the median side of the adrenal gland. Then, the splenic artery and vein are exposed, as also the left renal vein. Finally, the main adrenal vein can be found and sectioned between two clips.
On each side, dissection is completed with the robotic hook and the bipolar forceps and the gland is removed using a specimen retrieval bag.

\section{Post-operative care}

Pain is controlled by non-opioid intravenous analgesics. Patients are allowed to drink and eat 3 to 4 hours after surgery respectively. No drain is needed. Prophylaxis of deep vein thrombosis is given according to hospital protocol. Patients are discharged on the first or second day after surgery. Same day surgery is possible and currently promoted.

\section{Conclusions}

Overcost due to the robotic system is currently difficult to justify because no prospective randomized study has been published to show its superiority compared to a laparoscopic approach. We can affirm that robotic approach is safe and feasible for all adrenal pathology except very large adrenocortical tumor with adjacent organ invasion. We are convinced that the robotic system is the most useful for adrenalectomy of large tumors, obese patients, and in complex cases (e.g., vena cava clamping and suture) but this remains to be validated. At last, robotic approach can also decrease morbidity due to the learning curve when use of the second console is possible in a training phase.

\section{Acknowledgments}

None.

\section{Footnote}

Conflicts of Interest: The authors have no conflicts of interest to declare.

Ethical Statement: The authors are accountable for all aspects of the work in ensuring that questions related to the accuracy or integrity of any part of the work are appropriately investigated and resolved.

\section{References}

1. Shen WT, Sturgeon C, Duh QY. From Indicidentaloma to adrenocortical carcinoma: The surgical management of adrenal tumors. J Surg Oncol 2005;89:186-92. 
2. Thompson GB, Grant CS, van Heerden JA, et al. Laparoscopic versus open posterior adrenalectomy: a casecontrol study of 100 patients. Surgery 1997;122:1132-6.

3. Hyams ES, Stifelman MD. The role of robotics for adrenal pathology. Curr Opin Urol 2009;19:89-96.

4. Giulianotti PC, Buchs NC, Addio P, et al. Robot-assisted adrenalectomy: a technical option for the surgeon? Int J Med Robot 2011;7:27-32.

5. Brunaud L, Ayav A, Zarnegar R, et al. Prospective evaluation of 100 robotic-assisted adrenalectomies. Surgery 2008;144:995-1001.

6. D'Annibale A, Lucandri G, Monsellato I, et al. Robotic adrenalectomy: technical aspects, early results and learning curve. Int J Med Robot 2012;8:483-90.

7. Pineda-Solís K, Medina-Franco H, Heslin MJ. Robotic versus laparoscopic adrenalectomy: a comparative study in a high-volume center. Surg Endosc 2013;27:599-602.

8. You JY, Lee HY, Son GS, et al. Comparison of robotic adrenalectomy with traditional laparoscopic adrenalectomy with a lateral transperitoneal approach: a single-surgeon experience. Int J Med Robot 2013;9:345-50.

9. Teo XL, Lim SK. Robotic assisted adrenalectomy: it is ready for prime time? Investig Clin Urol 2016;57:S130-46.

10. Makay O, Erol V, Ozdemir M. Robotic adrenalectomy. Gland Surg 2019;8:S10-6.

11. Heger P, Probst P, Hunter FJ, et al. Evaluation of open and minimally invasive adrenalectomy: a systematic review and network meta-analysis. World J Surg 2017;41:2746-57.

12. Winter JM, Talamini MA, Stanfield CL, et al. Thirty robotic adrenalectomies: a single institution's experience. Surg Endosc 2006;20:119-24.

13. Nordenström E, Westerdahl J, Hallgrimsson P, et al. A prospective study of 100 roboticallyassisted laparoscopic adrenalectomies. J Robot Surg 2011;5:127-31.

14. Agcaoglu O, Aliyev S, Karabulut K, et al. Robotic versus laparoscopic resection of large adrenal tumors. Ann Surg Oncol 2012;19:2288-94.

15. Aksoy E, Taskin HE, Aliyev S, et al. Robotic versus laparoscopic adrenalectomy in obese patients. Surg Endosc 2013;27:1233-6.

16. Aliyev S, Karabulut K, Agcaoglu O, et al. Robotic versus laparoscopic adrenalectomy for pheochromocytoma. Ann Surg Oncol 2013;20:4190-4.

17. Brandao LF, Autorino R, Zargar H, et al. Robot-assisted laparoscopic adrenalectomy: step-by-step technique and comparative outcomes. Eur Urol 2014;66:898-905.

18. Lee GS, Arghami A, Dy BM, et al. Robotic single-site adrenalectomy. Surg Endosc 2016;30:3351-6.
19. Greilsamer T, Nomine-Criqui C, Thy M, et al. Roboticassisted unilateral adrenalectomy: risk factors for preoperative complications in 303 consecutive patients. Surg Endosc 2019;33:802-10.

20. Economopoulos KP, Mylonas KS, Stamou AA, et al. Laparoscopic versus robotic adrenalectomy: A comprehensive meta-analysis. Int J Surg 2017;38:95-104.

21. Kahramangil B, Berber E. Comparison of posterior retroperitoneal and transabdominal lateral approaches in robotic adrenalectomy: an analysis of 200 cases. Surg Endosc 2018;32:1984-9.

22. Stefanidis D, Goldfarb M, Kercher KW, et al. SAGES Guidelines for minimally invasive treatment of adrenal pathology. Surg Endosc 2013;27:3960-80.

23. Mishra K, Maurice MJ, Bukavina L, et al. Comparative Efficacy of Laparoscopic Versus Robotic Adrenalectomy for Adrenal Malignancy. Urology 2019;123:146-50.

24. Gumbs AA, Gagner M. Laparoscopic adrenalectomy. Best Pract Res Clin Endocrinol Metab 2006;20:483-99.

25. Ariyan C, Strong VE. The current status of laparoscopic adrenalectomy. Adv Surg 2007;41:133-53.

26. Ippolito G, Palazzo FF, Sebag F, et al. Safety of laparoscopic adrenalectomy in patients with large pheochromocytoma: a single institution review. World J Surg 2008;32:840-4.

27. Palazzo FF, Sebag F, Sierra M, et al. Long-term outcomes following laparoscopic adrenalectomy for large solid adrenal cortex tumors. World J Surg 2006;30:893-8.

28. Morelli L, Tartaglia D, Bronzoni L, et al. Robotic assisted versus pure laparoscopic surgery of the adrenal glands: a case-control study comparing surgical techniques. Langenbecks Arch Surg 2016;401:999-1006.

29. Thompson LH, Nordenstrom E, Almquist M, et al. Risks Factors for complications after adrenalectomy: results for a comprehensive database. Langenbecks Arch Surg 2017;402:315-22.

30. Ball MW, Hemal AK, Allaf ME. International Consultation on Urological Disease and European. BJU Int 2017;119:13-21.

31. Coste T, Caiazzo R, Torres F. Laparoscopic adrenalectomy by transabdominal lateral approach: 20 years experience. Surg Endosc 2017;31:2743-51.

32. Samreen S, Fluck M, Hunsinger M, et al. Laparoscopic versus robotic adrenalectomy: a review of the national inpatient sample. J Robot Surg 2019;13:69-75.

33. Bodner J, Augustin F, Wykypiel H, et al. The Da Vinci robotic system for general surgical applications: a critical interim appraisal. Swiss Med Wkly 2005;135:674-8. 
34. Feng Z, Feng MP, Feng DP, et al. A cost-conscious approach to robotic adrenalectomy. J Robot Surg 2018;12:607-11.

35. Plerhoples TA, Hernandez-Boussard T, Wren SM. The aching surgeon: a survey of physical discomfort and symptoms following open, laparoscopic, and robotic surgery. J Robot Surg 2012;6:65-72.

36. Elhage O, Challacombe B, Shortland A, et al. An

Cite this article as: Nomine-Criqui $\mathrm{C}$, Demarquet L, Schweitzer ML, Klein M, Brunaud L, Bihain F. Robotic adrenalectomy: when and how? Gland Surg 2020;9(Suppl 2):S166S172. doi: $10.21037 /$ gs.2019.12.11 assessment of the physical impact of complex surgical tasks on surgeon error and discomfort: a comparison between robot-assisted, laparoscopic and open approach. BJU Int 2015;115:274-81.

37. Nomine-Criqui C, Moog S, Bresler L, et al. Operative technique: Transperitoneal robotic adrenalectomy. J Visc Surg 2018;155:50-8. 